\title{
Commentary: Efficacy and Safety of Transcranial Direct Current Stimulation as an Add-on Treatment for Bipolar Depression: A Randomized Clinical Trial
}

\author{
Zhen-Yu Hu${ }^{\dagger}$, Xiaoli Liu ${ }^{\dagger}$, Hong Zheng ${ }^{\dagger}$ and Dong-Sheng Zhou* \\ Ningbo Kangning Hospital, Ningbo, China
}

Keywords: transcranial direct current stimulation (tDCS), bipolar depression, dorsolateral prefrontal cortex, Hamilton depression rating scale (HAMD), randomizad controlled trial

\section{A commentary on}

Efficacy and Safety of Transcranial Direct Current Stimulation as an Add-on Treatment for Bipolar Depression: A Randomized Clinical Trial

by Sampaio-Junior, B., Tortella, G., Borrione, L., Moffa, A. H., Machado-Vieira, R., Cretaz, E., et al. (2018). JAMA Psychiatry 75, 158-166. doi: 10.1001/jamapsychiatry.2017.4040

\section{OPEN ACCESS}

Edited by:

Wenbo Luo,

Liaoning Normal University, China

Reviewed by:

Andrea De Bartolomeis,

Università degli Studi di Napoli

Federico II, Italy

Dandan Zhang,

Shenzhen University, China

*Correspondence:

Dong-Sheng Zhou

wyzhouds@sina.com

tThese authors have contributed equally to this work

Received: 12 July 2018 Accepted: 16 November 2018 Published: 03 December 2018

Citation:

Hu Z-Y, Liu X, Zheng H and Zhou D-S (2018) Commentary: Efficacy and

Safety of Transcranial Direct Current Stimulation as an Add-on Treatment for Bipolar Depression: A Randomized

Clinical Trial.

Front. Hum. Neurosci. 12:480.

doi: 10.3389/fnhum.2018.00480
Bipolar disorder is a severe, recurrent psychiatric disorder, characterized by repeated remission and deterioration (Soares-Weiser et al., 2007). Bipolar disorder causes a high burden medical care for the individuals and society (Ferrari et al., 2016). Compared to manic episode, depressive one is much more frequent and prolonged in bipolar disorder patients (Suppes et al., 2005). Currently there are several therapeutic approaches for bipolar depression (BD), including pharmacological treatment, electroconvulsive therapy (ECT), cognitive behavioral therapy (CBT) and repetitive transcranial magnetic stimulation (rTMS) (Judd et al., 2002; Okumura and Ichikura, 2014; Blumberger et al., 2018).

Transcranial direct current stimulation (tDCS) is a non-invasive brain stimulation (NIBS) method with proven efficacy for neuropsychiatric disorders. It is also easily portable, with low cost and simple for manipulation. It delivers a weak current to the cortex through scalp electrodes and then induces changes in cortical excitability (Chang et al., 2015). Anodal stimulation facilitates depolarization of neurons, which enhances the cortex excitability, cathodal stimulation leads to hyperpolarization of neurons, which inhibits the cortex function (Nitsche et al., 2003; Hasan et al., 2011). tDCS stimulation leads to changes in connected cortical and subcortical regions as well (Stagg et al., 2010; Lang et al., 2015). Previous studies demonstrated the prospective potential of tDCS in unipolar depression (Shiozawa et al., 2014; Brunoni et al., 2016). However, few studies have been conducted on the treatment effectiveness of tDCS in BD.

Recently, Sampaio-Junior et al. conducted the first randomized sham-control clinical trial on 59 subjects, which intended to determine the efficacy and safety of tDCS for BD (Sampaio-Junior et al., 2018). Requirements for the participants are between the ages of 18 and 65, diagnosed BD, Hamilton Depression Rating Scale (HDRS-17) scored higher than 17, low suicide risk (evaluated by Mini-International Neuropsychiatric Interview questionnaire), in stable condition after 4-week pharmacologic treatment. The connections to the stimulator were concealed so that neither experimenter nor participant could determine the polarity of stimulation. HDRS-17, Montgomery-Åsberg Depression Rating Scale, Clinical Global Impression(CGI) depression scale, cumulative 
responses (defined as from baseline, HDRS-17 scores reduced $>50 \%$ at week $2,4,6$ ), remission rates were totally assessed at baseline, week 2 , week 4 , and week 6 . In addition, rates of adverse events were recorded at week 2, 6 .

Similar to many tDCS and rTMS studies, the clinical trial was administered to dorsolateral prefrontal cortex (DLPFC), which is a core region involves in cognitive control and emotion modulation. The location of DLPFC was determined by EASYstrap, a better positioning method compared to other methods. The anode (left) and cathode (right) electrode were placed on the bilateral DLPFC, respectively. 12 sessions of $2 \mathrm{~mA}$ (30 min) tDCS were performed, ten of which applied daily from Monday to Friday, with weekends off, two of which were performed at week 4 and 6 (study end point). The treatment schedule was same to previous studies, which made the results comparable (Brunoni et al., 2013).

The randomized sham-control trial continued for nearly 2 years. In active tDCS group, HDRS-17 score declined significantly when compared to the baseline. Through KaplanMeier analysis, the add-on intervention group shown to be more efficacious than sham group, showing higher cumulative response rate and remission rate. In addition, the change of Montgomery-Åsberg Depression Rating Scale indicated that active tDCS group had significant improvements than sham group $(P<0.05$, but not significant in CGI). Besides skin redness, other adverse event rates were insignificantly different between active and sham group at each time point.

Previous studies only conducted small sample sized openlabel protocol in mixed population of unipolar-bipolar subjects (Brunoni et al., 2012; Palm et al., 2012). The study was the first randomized double-blind sham-control trial to confirm the efficacy and safety of prefrontal tDCS applied to BD. The study would provide insights for further large multi-center studies. In addition, as we all know the BD patients suffered cognitive impairment (Wingo et al., 2009), it raises a concern whether tDCS treatment would enhance BD cognitive behaviors such as working memory, emotion process, attention bias and so on.

There are still some limitations in the present study. First, it is unknown if active tDCS was superior than sham in sustained

\section{REFERENCES}

Blumberger, D. M., Vila-Rodriguez, F., Thorpe, K. E., Feffer, K., Noda, Y., Giacobbe, P., et al. (2018). Effectiveness of theta burst versus high-frequency repetitive transcranial magnetic stimulation in patients with depression (THREE-D): a randomised non-inferiority trial. Lancet 391, 1683-1692. doi: 10.1016/S0140-6736(18)30295-2

Brunoni, A. R., Ferrucci, R., Bortolomasi, M., Scelzo, E., Boggio, P. S., Fregni, F., et al. (2012). Interactions between transcranial direct current stimulation (tDCS) and pharmacological interventions in the Major Depressive Episode: findings from a naturalistic study. Eur. Psychiatry 28, 356-361. doi: 10.1016/j.eurpsy.2012.09.001

Brunoni, A. R., Moffa, A. H., Fregni, F., Palm, U., Padberg, F., Blumberger, D. M., et al. (2016). Transcranial direct current stimulation for acute major depressive episodes: meta-analysis of individual patient data. Br. J. Psychiatry J. Ment. Sci. 208:522. doi: 10.1192/bjp.bp.115.164715 remission. Perhaps this is due to the fact that remission analysis or tDCS design was not optimal? Second, CGI depression scale might not be sensitive for current sample population-given the less severity. Third, though utilizing proper randomization methods, the random distributions of baseline variables of the small sample were imbalanced. Forth, in integrity of blinding, as nearly three-fifths participants of each group identified correctly the allocation group, which might cause guinea pig effect.

In conclusion, the trial based on small sample presented the effectiveness, tolerance and safety of tDCS in bipolar depression patients. The promising result also inspires further research to demonstrate the efficacy of tDCS on BD in a large sample. Neuroscience studies indicated that individuals with BD displays cognitive deficits (Depp et al., 2016), so whether add-on tDCS intervention showing positive impacts on cognition requires more explorations.

The underlying neural mechanism of why tDCS can treat BD is yet unknown. Neuroplasticity as a neurophysiologic condition for depression is well recognized (Henn and Vollmayr, 2004), which is unclear if this is the case for BD patients. It is possible that $\mathrm{tDCS}$ induced neuroplasticity might contribute to alleviation of unipolar depression symptoms (Nitsche et al., 2009), which warrants further investigation.

\section{AUTHOR CONTRIBUTIONS}

D-SZ designed the study. Z-YH, XL performed and write the study. HZ contributed to revised work. All authors have read and approved the final version of the manuscript.

\section{FUNDING}

The study was supported by the Medical Science and Technology Project in Ningbo (2016A37, 2017A10) and the Major Science and Technology Projects in Ningbo, Zhejiang Province, China (2017C510012).

\section{ACKNOWLEDGMENTS}

The authors thank their department for supports.

Brunoni, A. R., Valiengo, L., Baccaro, A., Zanão, T. A., de Oliveira, J. F., Goulart, A., et al. (2013). The sertraline vs. electrical current therapy for treating depression clinical study: results from a factorial, randomized, controlled trial. JAMA Psychiatry 70, 383-391. doi: 10.1001/2013. jamapsychiatry.32

Chang, M. C., Kim, D. Y., and Park, D. H. (2015). Enhancement of cortical excitability and lower limb motor function in patients with stroke by transcranial direct current stimulation. Brain Stimulat. 8, 561-566. doi: 10.1016/j.brs.2015.01.411

Depp, C. A., Dev, S., and Eyler, L. T. (2016). Bipolar depression and cognitive impairment: shared mechanisms and new treatment avenues. Psychiatr. Clin. North Am. 39, 95-109. doi: 10.1016/j.psc.2015.09.004

Ferrari, A. J., Stockings, E., Khoo, J. P., Erskine, H. E., Degenhardt, L., Vos, T., et al. (2016). The prevalence and burden of bipolar disorder: findings from the Global Burden of Disease Study 2013. Bipolar Disord. 18, 440-450. doi: $10.1111 /$ bdi. 12423 
Hasan, A., Nitsche, M. A., Rein, B., Schneider-Axmann, T., Guse, B., Gruber, O., et al. (2011). Dysfunctional long-term potentiation-like plasticity in schizophrenia revealed by transcranial direct current stimulation. Behav. Brain Res. 224, 15-22. doi: 10.1016/j.bbr.2011.05.017

Henn, F. A., and Vollmayr, B. (2004). Basic pathophysiological mechanisms in depression: what are they and how might they affect the course of the illness? Pharmacopsychiatry 37, 152-156. doi: 10.1055/s-2004-832670

Judd, L. L., Akiskal, H. S., Schettler, P. J., Endicott, J., Maser, J., Solomon, D. A., et al. (2002). The long-term natural history of the weekly symptomatic status of bipolar I disorder. Arch. Gen. Psychiatry 59, 530-537. doi: 10.1001/archpsyc.59.6.530

Lang, N., Siebner, H. R., Ward, N. S., Lee, L., Nitsche, M. A., Paulus, W., et al. (2015). How does transcranial DC stimulation of the primary motor cortex alter regional neuronal activity in the human brain? Eur. J. Neurosci. 22, 495-504. doi: 10.1111/j.1460-9568.2005.04233.x

Nitsche, M. A., Kuo, M. F., Karrasch, R., Wächter, B., Liebetanz, D., and Paulus, W. (2009). Serotonin affects transcranial direct current-induced neuroplasticity in humans. Aktuelle Neurologie 66:503. doi: 10.1016/j.biopsych.2009.03.022

Nitsche, M. A., Liebetanz, D., Lang, N., Antal, A., Tergau, F., and Paulus, W. (2003). Safety criteria for transcranial direct current stimulation (tDCS) in humans. Clin. Neurophysiol. 114, 2220-2222. doi: 10.1016/S1388-2457(03) 00235-9

Okumura, Y., and Ichikura, K. (2014). Efficacy and acceptability of group cognitive behavioral therapy for depression: a systematic review and meta-analysis. $J$. Affect. Disord. 164, 155-164. doi: 10.1016/j.jad.2014.04.023

Palm, U., Schiller, C., Fintescu, Z., Obermeier, M., Keeser, D., Reisinger, E., et al. (2012). Transcranial direct current stimulation in treatment resistant depression: a randomized double-blind, placebo-controlled study. Brain Stimulat. 5, 242-251. doi: 10.1016/j.brs.2011.08.005

Sampaio-Junior, B., Tortella, G., Borrione, L., Moffa, A. H., MachadoVieira, R., Cretaz, E., et al. (2018). Efficacy and safety of transcranialdirect current stimulation as an add-on treatment for bipolar depression: a randomized clinical trial. JAMA Psychiatry 75, 158-166. doi: 10.1001/jamapsychiatry.2017.4040

Shiozawa, P., Fregni, F., Benseñor, I. M., Lotufo, P. A., Berlim, M. T., Daskalakis, J. Z., et al. (2014). Transcranial direct current stimulation for major depression: an updated systematic review and meta-analysis. Int. J. Neuropsychopharmacol. 17, 1443-1452. doi: 10.1017/S1461145714000418

Soares-Weiser, K., Bravo Vergel, Y., Beynon, S., Dunn, G., Barbieri, M., Duffy, S., et al. (2007). A systematic review and economic model of the clinical effectiveness and cost-effectiveness of interventions for preventing relapse in people with bipolar disorder. Health Technol. Assess 11, iii-iv, ix-206. doi: $10.3310 /$ hta11390

Stagg, C. J., O'Shea, J., Kincses, Z. T., Woolrich, M., Matthews, P. M., and JohansenBerg, H. (2010). Modulation of movement-associated cortical activation by transcranial direct current stimulation. Eur. J. Neurosci. 30, 1412-1423. doi: 10.1111/j.1460-9568.2009.06937.x

Suppes, T., Kelly, D. I., and Perla, J. M. (2005). Challenges in the management of bipolar depression. J. Clin. Psychiatry 66, 11-16.

Wingo, A. P., Harvey, P. D., and Baldessarini, R. J. (2009). Neurocognitive impairment in bipolar disorder patients: functional implications. Bipolar Disord. 11, 113-125. doi: 10.1111/j.1399-5618.2009. 00665.x

Conflict of Interest Statement: The authors declare that the research was conducted in the absence of any commercial or financial relationships that could be construed as a potential conflict of interest.

Copyright $@ 2018 \mathrm{Hu}$, Liu, Zheng and Zhou. This is an open-access article distributed under the terms of the Creative Commons Attribution License (CC BY). The use, distribution or reproduction in other forums is permitted, provided the original author(s) and the copyright owner(s) are credited and that the original publication in this journal is cited, in accordance with accepted academic practice. No use, distribution or reproduction is permitted which does not comply with these terms. 